\title{
Professional Development (PD) Design for Undergraduate Physics Instruction
}

\author{
Ozden Sengul \\ Georgia State University, Atlanta, USA
}

\begin{abstract}
Research-based instructional strategies in physics education aim to promote student-centered instruction to enhance students' conceptual understanding. However, adopting these innovative approaches may be challenging for physics instructors. The change in instructional strategies may occur in developmental stages through extensive professional development (PD) involving planning, implementation, and reflection. This paper provides a PD model for the physics faculty to employ active learning strategies. The model includes three phases and requires at least four years adopting and maintaining research-based strategies through examples and suggestions as a guide to the implementation process.
\end{abstract}

Keywords: faculty development, PD, teaching and learning, physics education

\section{Introduction}

Physics education research (PER) has developed research-based instructional strategies (RBISs) to overcome students' learning difficulties and transform undergraduate physics instruction from a transmissionist to a student-centered approach (Mervis, 2013; Henderson \& Dancy, 2007; Singer, Nielsen, \& Schweingruber, 2012). The work of PER focuses on enhancing students' active learning to support students' meaningful learning experiences and develop conceptual understanding through designing instructional tools and strategies. However, changing instructional practices and conceptions is a complex issue (Dancy \& Henderson, 2007). Direct use of RBISs may not address the limitations of a particular classroom situation. A physics instructor may be aware of RBISs, but prefer to use the strategy as it is or may not successfully disseminate those strategies in their contexts and return to traditional approaches.

Getting physics instructors to accept new approaches occurs in progressive stages guided through explicit planning and implementation (Middendorf, 1999; 2004). Physics instructors need to participate in a professional development (PD) program to support their learning of RBISs and develop their knowledge, skills, beliefs, and attitudes (Capps, Crawford, \& Constas, 2012; Henderson \& Dancy, 2011). This will allow them to make modifications on the innovations for their specific classroom context, examine their students' thinking for successful implementation, and obtain higher learning gains (Hodges, 2006; Wilson, 2013). They need to develop a professional stance to disseminate the instructional innovations through repeated practice and sufficient reflection.

Henderson and Dancy (2011) recommended four types of interaction between change agents and instructors including adoption, adaptation, reinvention, and invention. Change agents suggest a particular

Ozden Sengul, Ph.D., Middle and Secondary Education, Georgia State University. 
pedagogical strategy depending on the needs and interests of the instructors. Instructors may directly adopt the innovation without any modification (Adoption) or transform slightly for implementation (Adaptation). Change agents mainly guide to the adoption and adaptation stages. There may be an inconsistency between the curriculum and students' needs or between the curriculum and instructors' conceptions, so that modifying the curriculum may have a positive influence on students' learning. As physics instructors develop knowledge about the strategy and students' learning, they learn how to customize and invent or reinvent the innovation based on the needs of the instruction.

Physics instructors need extended support to successfully implement the RBISs (Heck et al., 2012; Wilson, 2013). To address this need, this paper aimed to elaborate on Henderson and Dancy's (2011) four types of interaction and develop a professional development model to promote changes in physics instructors' beliefs and practices towards student-centered instruction and enhance student learning. The following of the paper addresses a design model for the dissemination of RBISs in a physics department. The proposed PD model has three phases, in which Phase-I is a detailed investigation of prior conditions, Phase-II addresses the development of knowledge base about the research-based strategies to decide to adopt or reject, and Phase-III is the process of implementation and confirmation.

\section{Diffusion of Innovation Model (Rogers, 1962)}

"Diffusion of Innovations" model by Rogers (1962) focuses on the dissemination of an evidence-based innovation through multiple communication channels including interpersonal and mass media channels (Rogers, 2010). The model is widely used to systematize the evolutionary process of changes in different fields, such as education, public health, and marketing. This PD design for undergraduate physics education embraced the Rogers' model as a guide to the dissemination of RBISs - active learning methods developed by PER community to understand and conceptualize the challenge of the process in a physics department willing to initiate reform in teaching and learning physics. Three phases of the model included six stages: prior conditions, knowledge about the innovation, persuasion for the advantages, a decision whether to adopt or reject the innovation, implementation, and confirmation to continue implementing the innovation. These three phases assumed to take four years to embrace the use of RBISs, but the duration can change based on the specific research context. Figure 1 provides the cycle of the PD model.

\section{Phase 1: Investigating Prior Conditions}

Prior conditions. Active learning strategies are useful in enhancing the student learning in different contexts (Singer et al., 2012). In spite of this evidence from the literature, physics instructors resist increasing the uncertainty and conflict in the classroom due to situational and personal barriers including traditional conceptions, time, motivation, experience, control, expertise, effort, fear, and rewards (Henderson \& Dancy, 2007; 2011). Instructors fear losing power, respect, and authority due to lack of training, feelings of isolation, content coverage, grading challenges, and peer and student evaluations (Hodges, 2006). Instructors may have concerns about how much the change process will take or how their participation can influence their practice (Middendorf, 2004). While asking physics instructors to change their instructional practices into student-centered approach by adopting active learning strategies, change agents have significant roles like developing a need for change or diagnosing problems, establishing an information exchange relationship, and addressing the fundamental concerns as necessary and timely topics in the planning to diffuse them without 
discontinuance (Rogers, 2010). Change agents (such as PD designers) are prominent participants of the change process to help physics instructions experience the adoption of new ideas or RBISs and engage in a network of PERs and other practitioners and to provide resources, such as curricular materials and instructional strategies (Edwards, Sandoval, \& McNamara, 2015; Henderson, Beach, \& Finkelstein, 2011; Rogers, 2010). Besides, the change agents identify the areas that physics instructors need improvement, generate ideas, and make suggestions about the appropriate innovation to diffuse and communicate the knowledge of the innovation to a network of physics instructors (Edwards et al., 2015; Rogers, 2010).

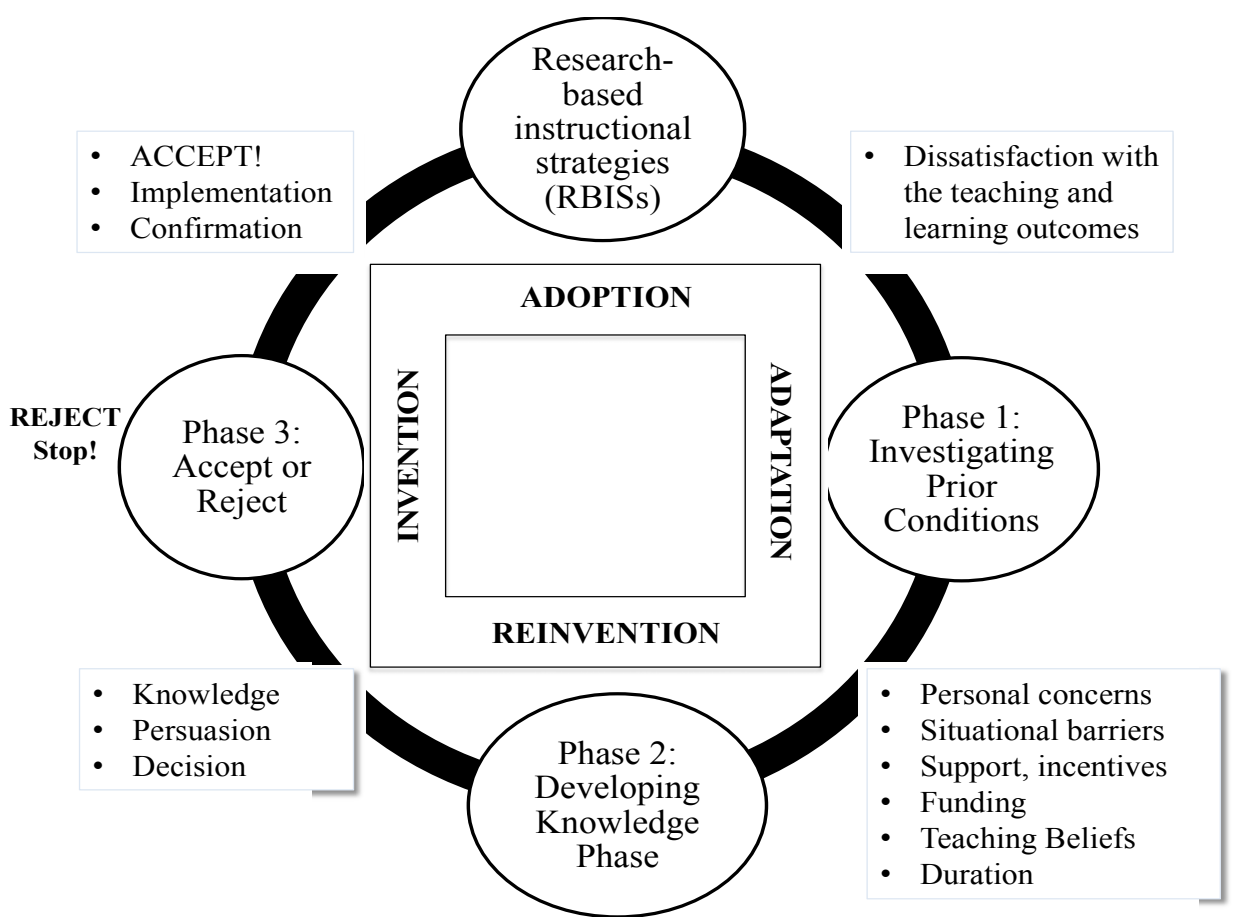

Figure 1. PD model (Modified from Henderson \& Dancy, 2007).

The dissemination of RBISs provides a chain of "social network" to promote the change through providing resources and incentives (Rogers, 2010). A more significant group influences the process of change in the instructional practices, such as colleagues, the department administrators, university (including resources), disciplinary connections, and education society. For example, support from administrators can enhance instructors' motivation for change and help the spread of information (Middendorf, 2004). Peer coaching and experts, who created the innovation, can provide interactions and learning experiences to be transferred to their classroom contexts (Marshall \& Smart, 2013). An opinion leader can be the person, who has higher social status and is innovative, so that physics instructors ask questions when they need to use a new technology (Rogers, 2010). The opinion leader can help with the planning and communication through representing the norms of the faculty, providing information or solution about the needs and problems (Middendorf, 2004).

Sunal et al. (2001) suggested that support from administrators, who have resources, commitment, and the respect, such as Dean, Associate Dean, and Department Chair can contribute to making the innovation as part of a more extensive system within the university and can motivate instructors for change. For example, physics faculty can be recognized for their contributions to student learning through a note, plague, luncheon, internal 
and teaching grants for resources and technological support (Diamond, 2002). As an external resource, National Science Foundation (NSF, 2005) supports the improvement of science, technology, engineering, and mathematics (STEM) education through exploration-design and development-implementation projects. Adopting and maintaining an educational change is also the process of revealing and challenging beliefs and conceptions towards the transformation in practices (Jones \& Leagon, 2014). Pundak and Rozner (2008) suggested that instructor's decisions for change are influenced by their beliefs about teaching and learning, their prior teaching practices, and the norms of the department. Physics instructors should be dissatisfied with their teaching conceptions and practices or with their students' poor preparation, lack of interest, and low learning gains (Henderson, 2005). Being aware of the RBISs and the problems in their practices and students' learning can improve instructors' motivation to make changes in the practices and enhance student learning.

High-quality PD. High-quality PD is structured around "collaboration, inquiry, and reflection" providing a broad and sustained change in practices (Edwards et al., 2015; Wilson, 2013). According to Desimone (2009), PD is a slow, thoughtful, and conscious decision-making process. Short-term workshops have not been found useful in providing sustainability and fostering positive beliefs for instructional improvement (Edwards et al., 2015; Loucks-Horsley, Love, Stiles, Mundry, \& Hewson, 2003). Physics instructors need time and effort to transfer their knowledge into practice. Longer PD programs with follow-up and guidance can result in more significant changes. Although there is no particular agreement on the duration of a PD program, research suggests that teachers should involve in "at least 80 hours" on-going training (Loucks-Horsley et al., 2003; Marshall \& Smart, 2013). Osborne and colleagues (2013) also recommended experiencing at least two-years implementation of innovative strategies to promote the change. Therefore, effective dissemination of RBISs depends on a systematic and comprehensive approach, sufficient time, mentoring for planning and teaching, creating networks, resources, technical support, and incentives. This change is intrinsically a challenging and long-term evolutionary process and requires the acquisition of new skills and beliefs. It is essential to focus on a few changes rather than trying several changes at once, expect the problems to occur and have available time and energy.

A model institution. The author suggests the readers consider a physics department with diverse student demographics in an urban university teaching physics in traditional lectures with nearly 50 students in four-hours a week. For lecture format, lab and lecture are separate, and the experiments are in the cookbook-type laboratory investigations and taught for two-hours per week for algebra-based classes and three-hours per week for calculus-based courses (including one-hour tutorial recitation session and two-hours laboratory session). On the other hand, the department initiated the use of "Studio Physics" format in some algebra-based physics classes based on North Caroline State University (NCSU)'s Student-Centered Active Learning Environment for Undergraduate Programs (SCALE-UP) model (Beichner et al., 2007). In both types of classes (lecture or studio physics), the average learning gain from Force Concept Inventory (FCI) is low based on Hake's (1998) definition that introductory courses with normalized gain less than 0.30 to be low-gain courses.

Considering the suggestions of PER groups, physics department increases interest to develop a vision and coherence for curriculum materials and instructional strategies that will challenge the teaching beliefs, knowledge, experiences, and students' needs (Heck et al., 2012). With the administrators' support, physics department head initiates a reform to redesign the physics classes that can provide active engagement activities 
and produce the alternative learning materials (Redish, 2003). Both traditional and studio physics formats will be restructured in the PD model, and instructional plan and learning materials will be prepared considering each classroom context. The department has funding, technical support, and computer-rich laboratory classes available. Opinion leaders are selected as an experienced faculty members, computer help technicians, and laboratory and class technicians.

In the first phase, change agents will conduct open-ended interviews with physics faculties about their teaching experiences and conceptions of teaching and learning. Interviews with the instructors will be undertaken to investigate what factors influence their actions, evolution of their teaching philosophy, and their understanding of student learning. Administrators will also be interviewed to collect data about the history and reasons of department policy and culture as well as student and instructor characteristics. The change agents will also make classroom observations using research-based observation protocols, such as Reformed Teaching Observation Protocol (RTOP) (Pilburn et al., 2000) to evaluate the use of reform-based strategies or Teaching Dimensions Observation Protocol (TDOP) (Hora, Oleson, \& Ferrari, 2013) to describe the teacher behaviors and instructional practices. Investigation of prior conditions takes a semester-long study (for example, in a spring semester) and helps the change agents or researchers to understand the needs and behaviors of the physics faculty and their students' learning.

\section{Phase 2: Development of Knowledge Base}

Physics instructors should be aware of the need for change. Change agents should support physics instructors to reduce their resistance toward change and respond to their concerns regarding failure. They can suggest alternatives by identifying and addressing the problems in practice, providing evidence for the implementation and from the literature (Heck et al., 2012). Physics instructors need to understand what they are asked to do and how innovative strategies will improve their implementation without tending to return to the traditional methods. Adoption cannot be learned through simple modeling or in a linear process, which is a dynamic and iterative process and requires experience, knowledge base, and complex approaches through diffusion of innovations at both an individual and organizational level (Pundak\&Rozner, 2008; Rogers, 2010; Siddiqui \& Adams, 2013). This PD design suggests that Phase-II includes knowledge, persuasion, and decision stages and takes nearly a year, although the time interval may change based on the learning process of instructors.

Knowledge. Physics instructors develop knowledge about innovative teaching methods in three stages suggested by Rogers (2010) including awareness-knowledge, how-to knowledge, and principles knowledge.

American Physical Society (APS), American Association of Physics Teachers (AAPT) conferences, workshops, such as New Faculty Workshop (NFW), and written descriptions of effective practices and course development highlight the use of RBISs (Heron \& Meltzer, 2005). Considering the needs of a model institution, change agents will organize a one-week intensive summer workshop (at least 30 hours) during a physics education conference, so that physics instructors have a chance to meet with a community of physics instructors, PERs, and experts. The workshop will mainly address the areas that the physics faculty needs help including fundamental topics in physics education research, such as active learning and interactive lectures (Mazur, 1997), recruiting and retaining physics major (NSF, 1996), using technology to teach physics (Beichner et al., 2007), and evaluation of the instruction and student learning through conceptual and attitude surveys, such as Force Concept Inventory (FCI) (Hestenes, Wells, \& Swackhamer, 1992). The workshops will also focus on creating 
awareness through learning how to use each strategy and its model implementations. Moreover, a PD guide may serve as a resource including the contents of the workshop, the essential information, practical activities, and resources, such as books, websites, publications, and some case study examples and episodes from the literature (Edwards et al., 2015). At the end of the summer workshop, PD participants will receive a copy of the PD guide, which will be introduced at the beginning of the fall semester through a second, but the relatively shorter workshop. This second workshop aims to demonstrate some instructional models to help instructors plan the order of events during the instruction.

Whitworth and Chiu (2015) suggested that besides awareness and developing knowledge about how to use a specific strategy to implement the innovation practically, instructors also need to know why a particular practice works - "functioning principles about how an innovation works and how to deal with the problems that arise during its implementation" (Pundak \& Rozner, 2008, p. 155). Physics instructors can learn about how to use an RBIS and why it works in a long-term evolutionary process through the social network, discussion, and preparation. As physics instructors are aware of RBISs that can have a considerable impact on improving student learning, they become dissatisfied with their teaching approach and identify the problems during the implementation of their methods (Henderson, 2005). In other words, they become curious, begin to ask questions, and look for information. Instructors' questions help change agents identify themes to address their needs, discuss how to solve a specific aspect of a problem, and facilitate the idea generation.

Persuasion. Based on the knowledge that the physics instructors acquire, they begin to develop a tendency either to adopt or to reject the PER-based strategies. According to Rogers (2010), there are five perceived characteristics of an innovation influencing the propensity to adopt. The change should be regarded as better than the current practice (relative advantage), compatible with the existing values and previous experiences and needs (compatibility), have perceived difficulty to understand and use (complexity), be experimented a little at a time instead of all at once (trialability), and have evident results for others (observability).

To resolve the problems and concerns identified in the knowledge stage, physics instructors begin to produce ideas through the support from the PD designers and change agents. After two introductory workshops, physics faculty is interested in the use of RBISs to enhance conceptual understanding along with the development of problem-solving skills, increase the involvement of diverse students with various learning abilities and motivation, and make students active participants of the learning process (Singer et al., 2012). In the model institution, the author assumes that physics instructors, lab coordinator, and opinion leaders from the department are curious about an instructional sequence, such as "5E Instructional Model" (Bybee et al., 2006), "Peer Instruction" (Mazur, 1997), and "Physlets" (Christian, Belloni, \& Dancy, 2001) for classroom instruction, "Introductory Physics Tutorials" (McDermott \& Shaffer, 1999), and "Cooperative Problem Solving" (Heller \& Heller, 2001) for recitation and homework problems, and "RealTime Physics" laboratories (Sokoloff, Thornton, $\&$ Laws, 1995) for laboratory components.

According to Hilsen and Wadsworth (2002), PD program should coordinate series of activities to enhance participation and knowledge of new strategies. Physics instructors seek for the innovation-evaluation information to reduce the uncertainty and their concerns related to the unexpected outcomes of the innovation (Rogers, 2010). Some instructors may not have confidence in their ability to accomplish the change. They can adopt as it is at first, but as they have problems in the implementation, they can decide to make modifications through reflection on their knowledge and practice and through having discussions with colleagues and change agents. Instructors should constitute teacher-learning communities, so that they can share their experiences 
(peer coaching) and identify the challenges of implementation and students' learning difficulties. In this process, they should have supportive guidance (online/on-site) from experts, change agents, their colleagues, and administrators to diffuse the concerns and modify the curriculum materials ${ }^{1}$.

In the fall semester, physics instructors will be devised into small support groups to work cooperatively with the change agents and experience the basic principles and functions of active learning methods (Henderson, Dancy, \& Niewiadomska-Bugaj, 2012). By adopting the small part of each research-based strategy, instructors will evaluate the strengths, weaknesses, and gaps of the innovations (Pundak \& Rozner, 2008). Small working groups meet once a week or once in two weeks in a face-to-face or online platform to discuss the changes, concerns, or reflections in the process of learning the strategies and the development of learning tasks associated with the RBISs. The large working group involves all the physics instructors in the department and meets once in two or three months to address the needs through model implementations, small activity development workshops, micro-teaching activities, or discussion sessions for video lectures (Heck et al., 2012). These activities can provide examples for physics instructors of how RBISs are implemented and sustained in a particular context. The plan should include pre- and post-evaluation activities to assess instructors' understanding of active learning strategies. These activities should also provide clear and practical suggestions to address their concerns (Heck et al., 2012) and be scheduled according to plan that physics instructors will have enough time to "learn, adapt, integrate, and reflect on" (Ely, 1990, p. 300).

Also, Samuelowicz and Bain (2001) suggested that the interaction between student and instructor serves as the active agent in the change process to influence students' learning conceptions. Students in undergraduate physics classes have differences in their characteristics, the level of preparation, perceptions, and attitudes towards learning physics, cultural backgrounds, motivation, and study habits (Onwuegbuzie, Slate, \& Schwartz, 2001; Meltzer, 2002; Wigfield \& Cambria, 2010). Besides being a teacher-learner, instructors can engage in a research process and collect data to understand diverse students' thinking, how students' idea about a subject develops, to closely review and discuss students' conceptions and how their learning process will be correlated with students' characteristics to improve instruction and learning materials accordingly. They should be encouraged to utilize research-based content surveys, such as FCI (Hestenes, Wells, \& Swackhamer, 1992) or Force and Motion Conceptual Evaluation (FMCE) (Thornton \& Sokoloff, 1998) and attitude surveys, such as Maryland Physics Expectations (MPEX) (Redish, Saul, \& Steinberg, 1998) to evaluate students' conceptual understanding and attitude development in physics.

Additionally, Stanley (2010) suggested providing sample case scenarios to facilitate discussion on teaching physics for diverse classrooms including how to be more inclusive in the curriculum and what the instructor's responsibility is. During large group meetings, instructors can be encouraged discussing their concerns about how to create an inclusive classroom and how to prepare learning tasks including multiple levels of complexity; they can provide evidence from classroom data and develop strategies to elicit students' conceptions (Little, Hauser, \& Corbishley, 2009). These discussions can help the physics instructors create a classroom environment and research-based resources and decide either to adopt the strategy or to consider a new instructional technique based on students' needs.

\footnotetext{
${ }^{1}$ Instructors will receive sufficient resources from the summer workshops. Besides the guide, the PD program will provide an online repository including the contents of the PD guide, schedule, and updates about the resources and program. Teaching assistants will also take part in the group activities.
} 
According to Heck et al. (2012), physics instructors adopt a new strategy if they can analyze the design and implementation. Physics instructors need to reflect on their practices and determine weaknesses, strengths, and concerns to intensify their knowledge by working in support groups, dealing with uncertainty, and committing extra time and effort towards planning. Reflective practice helps instructors frequently engage in evaluation and improvement of their instruction in ongoing cycles (McAlpine \& Weston, 2000). Instructors should be encouraged to collect data from their classroom practices as videotapes, samples of student work, instructional plan, and learning activities to provide evidence for their implementation and examine other instructors' experiences.

Borko (2004) suggested that instructors can also conduct clinical interviews with their students to learn their alternative conceptions and how these ideas play a role in students' learning process. This process may help the instructors develop an awareness of the role of student thinking and importance of listening to the students in preparing learning tasks accordingly. As they understand student thinking, they can design useful interactive group activities, online individual or collaborative homework activities, and multiple-choice exams (Redish, 2003) to address diverse students' needs and explore the strengths and limitations of students' learning to make modifications. In this way, physics instructors can have a chance to expand their knowledge through the reflections on their worries and doubts while adopting the innovative strategies. In the persuasion stage, they can develop a favorable or unfavorable attitude about the innovation.

Decision. After meeting personal concerns in the persuasion phase, physics instructors move to implementation concerns in spring and summer semesters. In this process, instructors focus on a strategy a little at a time to learn how to adapt, reinvent, or invent an innovation considering the limitations of their classroom situations and enhancing students' learning (Henderson \& Dancy, 2011). They focus on the development of learning activities and investigate student reactions. They utilize specific examples of the change in action, imagine worst case or success scenarios, and discuss to solve problems related to their teaching. They utilize specific examples of the change in action, imagine worst case or success scenarios, and discuss the problems related to their teaching towards resolution. They can also visit model classrooms to learn from other people's experiences in different contexts and have networked with peers through teleconferences or informal meetings.

Small as well as large-group meetings are functional as instructors collaborate to exchange ideas, problems, and experiences about their efforts to change the way they teach, select the activities, develop instructional materials, and support students' learning. Instructors need to commit time to the selection and preparation of learning materials. For example, if a physics instructor wants to incorporate simulations, the instructor needs to review thousands of simulations to choose only hundreds of them (Pundak \& Rozner, 2008). Physics instructors may also prefer reading the articles suggested by change agents to critique, discuss, and find something useful for their teaching practices.

Social interaction, networking, and external support can motivate instructors to have a learning experience to overcome the challenges of implementation and create ownership to accept (Kezar, 2011). Based on the level of understanding of the innovation, the instructor decides whether to adopt or reject the innovation. The decision may change in course of time depending on the implementation process, the level of success, or new information to reconsider the practice. The method of developing learning tasks and plan for implementation takes nearly one academic year (fall, spring, and summer semesters), and requires an effort to examine the advantages and disadvantages of an innovative learning environment critically. 


\section{Phase 3: Accept or Reject}

The physics instructor should be able to fit various teaching strategies into a tight schedule. Physics instructors may not implement the innovation as it is. The instructor may perform some part of the new teaching method or modify the implementation according to the classroom context. Through teaching and learning activities in the previous phases, instructors should be able to develop a comprehensive teaching and learning guide for the department that may be utilized for further implementations.

Implementation. Instructors need to be creative to develop various methods for the implementation of the innovative instructional strategies and incorporation of technology to overcome the challenges and find solutions that can fit their beliefs. Instructors will use the learning activities developed in the previous phases, but they can customize those actions based on the implementation problems. For example, Belloni, Christian, and Dancy (2004) defined "Physlets" as flexible technological resources that can be modified slightly (adaptation) or significantly (reinvention) according to teaching beliefs and students' needs after developing knowledge about how to use the innovation. Using the "Peer Instruction" (Mazur, 1997), a physics instructor may develop a new strategy to encourage students for reading. For example, the instructor may ask students to think about what they have learned, develop a question, and submit to the class. This process may help instructor experience the invention of the strategy based on the difficulties of implementation and students' learning (Henderson \& Dancy, 2007). In another example, "Cooperative Problem Solving in Physics" (Heller \& Heller, 2001) activities can be moved to an online system to create an interactive online discussion environment as homework.

In the implementation phase, physics instructors will enact their plans in class and reflect on the implementation process to make revisions. Different reactions and experiences can be identified through interviews, classroom observations, and working groups during the implementation process. While instructors are teaching physics with an alternative strategy, change agents conduct interviews to evaluate the challenges of both the instructors' teaching and students' learning processes, examine the teaching strategies used in the implementation of the innovation, and assess the effectiveness of the practice on the student and teacher attitudes. Interviews can be conducted at the beginning of the semester (the third week of the semester) and the end of the semester. In addition, to evaluate how instructors adopt the strategy, classroom observations are conducted to support the interview data and establish the degree of the implementation of the innovation. Administrators are also interviewed to learn how they evaluate the process of change. Lastly, students' conceptual understanding is evaluated through diagnostic tests and exams and correlated with student characteristics to evaluate the effectiveness of alternative strategy on students' learning.

Confirmation. The instructors' decision to continue using the active learning method depends on their satisfaction with the successful implementation. They need continuous support of change agents, administrators, and colleagues to answer their questions, analyze students' reactions, and make modifications on the implementation accordingly. The change agent has a significant role in understanding of the department system, promoting the transformation in pedagogical strategies, communication, and team building, and flexibility in the face of the unexpected, tolerance for ambiguity, and basic respect for others (Ellsworth, 2000). Change agents continue to make suggestions based on the results taken from interviews and observations from the implementation stage. The change agent should also check in frequently asking, "Do you need some help?" "Here's an article I thought you'd find of interest" (Middendorf, 1999) or provide just-in-time online resources 
or online mini-courses (Edwards et al., 2015). Peer coaching should continue with large group meetings to address new implementations and evaluate the students' achievement. Implementation and confirmation phases take nearly two academic years starting in the fall semester after decision phase and continues in the following four semesters with continuous support from the change agents, collaboration, and reflection. Figure 2 represents the structure of the change process and the interaction between the change agents and instructors.

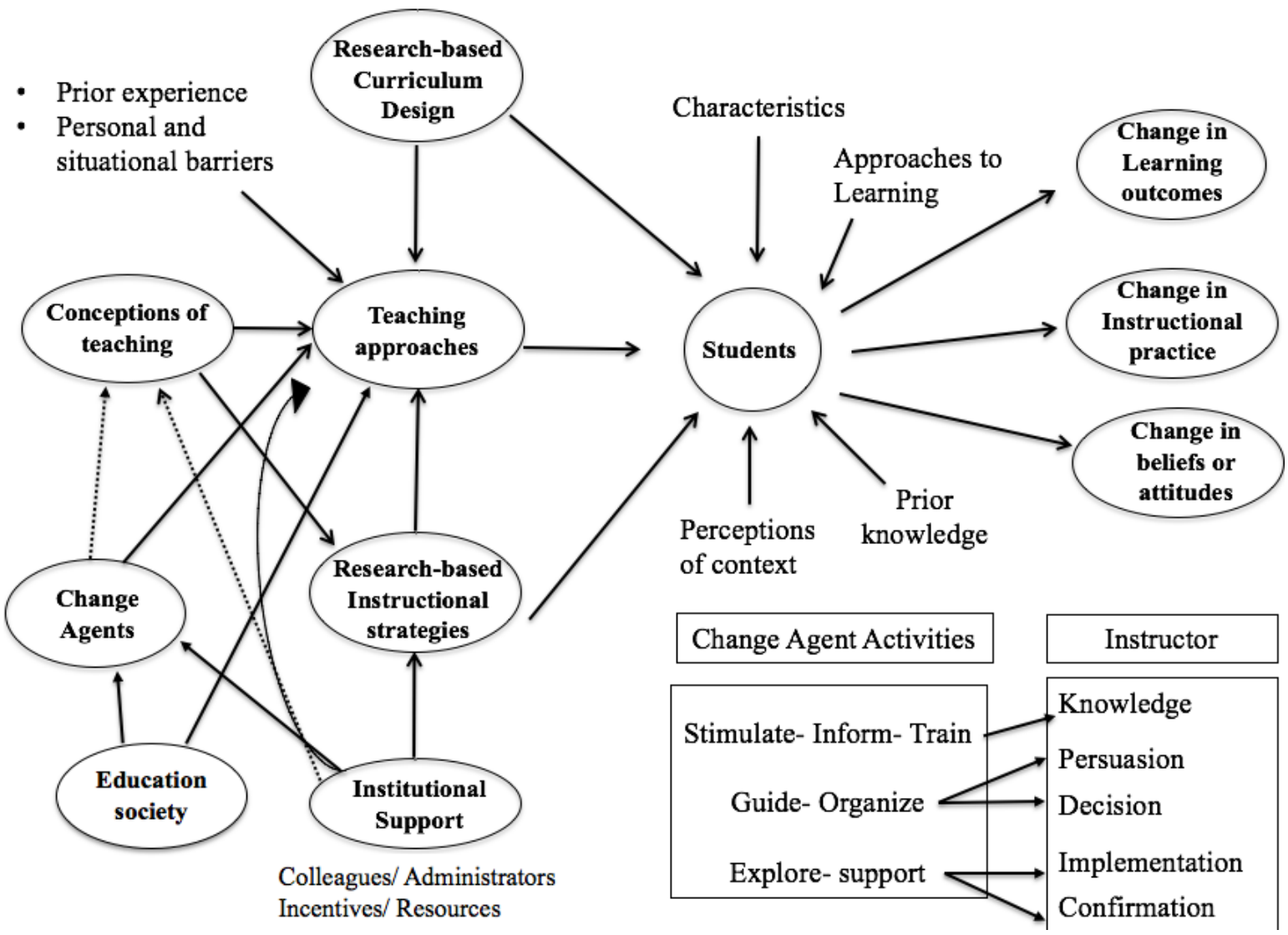

Figure 2. Components of the change process (Modified from Prosser et al., 1994, Prosser \& Trigwell, 1999, Havelock \& Zlotolow, 1995).

\section{Conclusion}

This PD model for the physics instructors is designed to be effective, efficient, responsive, faculty-centered, and faculty-owned (Edwards et al., 2015). The plan may allow the change agents to follow the concerns, difficulties, strengths, limitations, and improvements through eliciting prior-conditions, developing a knowledge-base, addressing concerns, and piloting implementation, and confirmation in a systematic way. The model may provide information about how a social-network building among change agents, PERs, experts from other universities, curriculum developers, incentives, and multiple resources support the improvement of instructional strategies and promote positive beliefs of teaching conceptions and practices for sustainable change. It is a slow process requiring the time commitment and energy. Physics instructors should be rewarded for their extra effort in the adoption of innovation. The implementation of this model may provide an example for dissemination of RBISs through focusing on the change in teaching beliefs and practices, and students' learning outcomes. 


\section{References}

Beichner, R. J., Saul, J. M., Abbott, D. S., Morse, J. J., Deardorff, D., Allain, R. J., ... \& Risley, J. S. (2007). The student-centered activities for large enrollment undergraduate programs (SCALE-UP) project. Research-Based Reform of University Physics, 1(1), 2-39.

Belloni, M., Christian, W., \& Dancy, M. H. (2004). Teaching special relativity using Physlets. The Physics Teacher, 42(5), $284-290$.

Borko, H. (2004). Professional development and teacher learning: Mapping the terrain. Educational Researcher, 33(8), 3-15.

Bybee, R. W., Taylor, J. A., Gardner, A., Van Scotter, P., Powell, J. C., Westbrook, A., \& Landes, N. (2006). The BSCS 5E instructional model: Origins and effectiveness. Colorado Springs, CO: BSCS, 5, 88-98.

Capps, D. K., Crawford, B. A., \& Constas, M. A. (2012). A review of empirical literature on inquiry professional development: Alignment with best practices and a critique of the findings. Journal of Science Teacher Education, 23(3), 291-318.

Christian, W., Belloni, M., \& Dancy, M. (2001). Physlets: Java tools for a web-based physics curriculum. In Computational Science_ICCS 2001 (pp. 1061-1073). Berlin: Springer Berlin Heidelberg.

Dancy, M., \& Henderson, C. (2007). Framework for articulating instructional practices and conceptions. Physical Review Special Topics-Physics Education Research, 3(1), 010103.

Desimone, L. M. (2009). Improving impact studies of teachers' professional development: Toward better conceptualizations and measures. Educational Researcher, 38(3), 181-199.

Diamond, R. M. (2002). Faculty, instructional, and organizational development: Options and choices. In K. H. Gillespie, L. R. Hilsen, and E. C. Wadsworth (Eds.), A guide to faculty development: Practical advice, examples, and resources (pp. 2-8). San Francisco, CA: Jossey-Bass.

Edwards, A. R., Sandoval, C., \& McNamara, H. (2015). Designing for improvement in professional development for community college developmental mathematics faculty. Journal of Teacher Education, 66(5), 466-481.

Ellsworth, J. B. (2000). Surviving change: A survey of educational change models. ERIC Clearinghouse on Information \& Technology, Syracuse University, 621 Skytop Rd., Suite 160, Syracuse, NY 13244-5290.

Ely, D. P. (1990). Conditions that facilitate the implementation of educational technology innovations. Journal of Research on Computing in Education, 23(2), 298.

Hake, R. R. (1998). Interactive-engagement versus traditional methods: A six-thousand-student survey of mechanics test data for introductory physics courses. American Journal of Physics, 66(1), 64-74.

Heck, D. J., Tarr, J. E., Hollebrands, K. F., Walker, E. N., Berry III, R. Q., Baltzley, P. C., ... \& King, K. D. (2012). Reporting research for practitioners: Proposed guidelines. Journal for Research in Mathematics Education, 43(2), 126-143.

Heller, K., \& Heller, K. (2001). Cooperative group problem solving in physics. Pacific Grove, CA: Brooks/Cole Publishing Company.

Henderson, C. (2005). The challenges of instructional change under the best of circumstances: A case study of one college physics instructor. American Journal of Physics, 73(8), 778-786.

Henderson, C., \& Dancy, M. H. (2007). Barriers to the use of research-based instructional strategies: The influence of both individual and situational characteristics. Physical Review Special Topics-Physics Education Research, 3(2), 020102.

Henderson, C., \& Dancy, M. H. (2011, February). Increasing the impact and diffusion of STEM education innovations. In Invited paper for the National Academy of Engineering, Center for the Advancement of Engineering Education Forum, Impact and Diffusion of Transformative Engineering Education Innovations. Retrieved from http://www.nae.edu/File.aspx

Henderson, C., Beach, A., \& Finkelstein, N. (2011). Facilitating change in undergraduate STEM instructional practices: An analytic review of the literature. Journal of Research in Science Teaching, 48(8), 952-984.

Henderson, C., Dancy, M., \& Niewiadomska-Bugaj, M. (2012). Use of research-based instructional strategies in introductory physics: Where do faculty leave the innovation-decision process? Physical Review Special Topics-Physics Education Research, 8(2).

Heron, P., \& Meltzer, D. (2005). The future of physics education research: Intellectual challenges and practical concerns. American Journal of Physics, 73(5), 390-394.

Hestenes, D., Wells, M., \& Swackhamer, G. (1992). Force concept inventory. The Physics Teacher, 30(3), 141-158.

Hilsen, L. R., \& Wadsworth, E. C. (2002). Staging successful workshops. In K. H. Gillespie, L. R. Hilsen, and E. C. Wadsworth (Eds.), A guide to faculty development: Practical advice, examples, and resources (pp. 108-122). San Francisco, CA: Jossey-Bass.

Hodges, L. C. (2006). Preparing faculty for pedagogical change: Helping faculty deal with fear. To Improve the Academy, 24(1), 121-134. 
Hora, M. T., Oleson, A., \& Ferrare, J. J. (2013). Teaching dimensions observation protocol (TDOP) user's manual. Madison: Wisconsin Center for Education Research.

Jones, M. G., \& Leagon, M. (2014). Science teacher attitudes and beliefs. In N. G. Lederman, and S. Abell (Eds.), Handbook of research on science education (pp. 1067-1104). New York: Routledge.

Kezar, A. (2011). What is the best way to achieve broader reach of improved practices in higher education? Innovative Higher Education, 36(4), 235-247.

Little, C. A., Hauser, S., \& Corbishley, J. (2009). Constructing complexity for differentiated learning. Mathematics Teaching in the Middle School, 15(1), 34-42.

Loucks-Horsley, S., Love, N., Stiles, K. E., Mundry, S., \& Hewson, P. W. (2003). Designing professional development for teachers of science and mathematics. Thousand Oaks, CA: Corwin Press.

Marshall, J. C., \& Smart, J. B. (2013). Teachers' transformation to inquiry-based instructional practice. Creative Education, 4(02), 132.

Mazur, E. (1997). Peer instruction (pp. 9-18). Upper Saddle River, NJ: Prentice Hall.

McAlpine, L., \& Weston, C. (2000). Reflection: Issues related to improving professors' teaching and students' learning. Instructional Science, 28(5), 363-385.

McDermott, L. C., \& Shaffer, P. S. (1998). Tutorials in introductory physics. Upper Saddle River, NJ: Prentice Hall.

Meltzer, D. E. (2002). The relationship between mathematics preparation and conceptual learning gains in physics: A possible "hidden variable" in diagnostic pretest scores. American Journal of Physics, 70(12), 1259-1268.

Mervis, J. (2013). Transformation is possible if a university really cares. Science, 340(6130), 292-296.

Middendorf, J. (1999). A case study in getting faculty to change. To Improve the Academy, 17(1), 203-224.

Middendorf, J. (2004). Facilitating a faculty learning community using the decoding the disciplines model. New Directions for

Teaching and Learning, 98, 95-107.

National Science Foundation (NSF). (1996). Shaping the future: New expectations for undergraduate education in science, mathematics, engineering and technology (NSF 96-139). Washington, DC: National Science Foundation.

National Science Foundation (NSF). (2005). Course, curriculum, and laboratory improvement (CCLI): A solicitation of the division of undergraduate education (DUE) (NSF 05-559). Arlington, VA: National Science Foundation.

Onwuegbuzie, A. J., Slate, J. R., \& Schwartz, R. A. (2001). Role of study skills in graduate-level educational research courses. The Journal of Educational Research, 94(4), 238-246.

Osborne, J., Simon, S., Christodoulou, A., Howell - Richardson, C., \& Richardson, K. (2013). Learning to argue: A study of four schools and their attempt to develop the use of argumentation as a common instructional practice and its impact on students. Journal of Research in Science Teaching, 50(3), 315-347.

Pilburn, M., \& Sawada, D. (2000). Reformed teaching observation protocol (RTOP): Reference manual. Tempe, AZ: Arizona Collaborative for Excellence in the Preparation of Teachers (ACEPT) Technical Report No. IN00-3.

Prosser, M., Trigwell, K., Hazel, E., \& Gallagher, P. (1994). Students' experiences of teaching and learning at the topic level. Research and Development in Higher Education, 16, 305-310.

Prosser, M., \& Trigwell, K. (1999). Understanding learning and teaching: The experience in higher education. UK: McGraw-Hill Education.

Pundak, D., \& Rozner, S. (2008). Empowering engineering college staff to adopt active learning methods. Journal of Science Education and Technology, 17(2), 152-163.

Redish, E. F. (2003). Teaching physics with the physics suite. CD: Wiley.

Redish, E. F., Saul, J. M., \& Steinberg, R. N. (1998). Student expectations in introductory physics. American Journal of Physics, 66(3), 212-224.

Rogerts, E. M. (2010). Diffusion of innovations. New York: Free Press; London: Collier Macmillian.

Samuelowicz, K., \& Bain, J. D. (2001). Revisiting academics' beliefs about teaching and learning. Higher Education, 41(3), 299-325.

Siddiqui, M. J. A., \& Adams, R. (2013). The challenge of change in engineering education: Is it the diffusion of innovations or transformative learning? In 2013 ASEE Annual Conference. Retrieved from http://www.asee.org/public/conferences/20/papers/7574/download

Singer, S. R., Nielsen, N. R., \& Schweingruber, H. A. (2012). Discipline-based education research. Washington, DC: The National Academies.

Sokoloff, D. R., Laws, P. W., \& Thornton, R. K. (1995). Real time physics: A new interactive introductory lab program. AAPT Announcer, 25(4), 37. 
Stanley, C. A. (2010). Conceptualizing, designing, and implementing multicultural faculty development activities. In K. Gillespie and D. Robertson (Eds.), A guide to faculty development (pp. 194-213). San Francisco, CA: Jossey-Bass.

Sunal, D. W., Hodges, J., Sunal, C. S., Whitaker, K. W., Freeman, L. M., Edwards, L., ... \& Odell, M. (2001). Teaching science in higher education: Faculty professional development and barriers to change. School Science and Mathematics, 101(5), 246-257.

Thornton, R. K., \& Sokoloff, D. R. (1998). Assessing student learning of Newton's laws: The force and motion conceptual evaluation and the evaluation of active learning laboratory and lecture curricula. American Journal of Physics, 66(4), 338-352.

Trigwell, K., \& Prosser, M. (1996). Changing approaches to teaching: A relational perspective. Studies in Higher Education, 21(3), 275-284.

Whitworth, B. A., \& Chiu, J. L. (2015). Professional development and teacher change: The missing leadership link. Journal of Science Teacher Education, 26(2), 121-137.

Wigfield, A., \& Cambria, J. (2010). Students' achievement values, goal orientations, and interest: Definitions, development, and relations to achievement outcomes. Developmental Review, 30(1), 1-35.

Wilson, S. M. (2013). Professional development for science teachers. Science, 340(6130), 310-313. 